\title{
LAPAROSCOPIC TRANS-ABDOMINAL PREPERITONEAL VERSUS LICHTENSTEIN REPAIR OF INGUINAL HERNIA: A COMPARATIVE STUDY.
}

\author{
1. MBBS, FCPS \\ Associate Professor \\ Department of Surgery \\ QAMC/BVH Bahawalpur. \\ 2. MBBS, FCPS \\ Senior Registrar \\ Department of Surgery \\ QAMC/BVH Bahawalpur. \\ 3. MBBS (Final Year) \\ QAMC Bahawalpur. \\ 4. MBBS \\ WMO \\ QAMC/BVH Bahawalpur.
}

Correspondence Address: Dr. Munawar Jamil

53B Garden Area Satellite Town

Bahawalpur.

drmunawarjamil@hotmail.com

Article received on:

26/07/2018

Accepted for publication:

28/12/2018

Received after proof reading:

25/06/2019

\begin{abstract}
Munawar Jamil ${ }^{1}$, Khurram Niaz ${ }^{2}$, Fatima Tahir ${ }^{3}$, Humaira Sobia ${ }^{4}$
ABSTRACT... To compare Laparoscopic transabdominal preperitoneal (TAPP) to open Lichtenstein inguinal hernia repair for operation time, acute postoperative pain, complications, hospital stay, time to return to work to find out which has better outcome. Study Design: A prospective randomised controlled trial. Setting: QAMC/BVH Bahawalpur; Pakistan. Period: July 2017 to June 2018. Materials and Methods: It included 50 patients, 32 in Lichtenstein group and 18 in TAPP group above the age of 18 years. Operation time, acute postoperative pain, complications, hospital stay, time to return to work were compared in two groups. Data analysis was done on SPSS 23 version. Results: Mean age of patients were $45 \pm 9.79$ and $44.95 \pm 9.82$ in Lichtenstein and laparoscopic group, $96 \%$ were male. Operation time was $37.96 \pm 13.66$ vs. $48.77 \pm 9.99$ (Min), hospital stay $2.28 \pm 0.79$ vs. $1.55 \pm 0.63$ (Days), time to return to work $13.20 \pm 4.75$ vs. $10.47 \pm 3.59$ (Days) in Lichtenstein and laparoscopic group respectively. Pain score was $6.1 \pm 1.9$ vs. $5.2 \pm 0.94$ in Lichtenstein and laparoscopic group. In immediate complications haematoma $6.25 \%$ vs. $0 \%$, seroma $3.12 \%$ vs. $11.11 \%$, wound infection $9.37 \%$ vs.5.55\%, visceral injury $0 \%$ vs. $5.5 \%$ in Lichtenstein to laparoscopic group respectively. In long term complications chronic pain $28.12 \%$ vs. $11.11 \%$, recurrence $3.12 \%$ vs.0\%, port site hernia $0 \%$ vs. $5.55 \%$, numbness $9.37 \%$ vs. $0 \%$ in Lichtenstein and Laparoscopic group respectively. Mortality was nil in both groups. Conclusion: Although there is insignificant difference in complication rate, Laparoscopic hernia repair is better than Lichtenstein repair in terms of less postoperative pain, less hospital stay and early return to work.
\end{abstract}

Key words: Hospital Stay, Laparoscopic Hernia Repair, Lichtenstein Repair, Postoperative pain, TAPP

Article Citation: Jamil M, Niaz K, Tahir F, Sobia H. Laparoscopic trans-abdominal preperitoneal versus lichtenstein repair of inguinal hernia: a comparative study. Professional Med J 2019; 26(7):1151-1155.

DOI: 10.29309/TPMJ/2019.26.07.3789

\section{INTRODUCTION}

Inguinal hernia is very common problem. Inguinal hernia account for $75 \%$ of all ventral hernias, $27 \%$ in men and $3 \%$ in women, so surgery for inguinal hernia are common. ${ }^{1}$ The surgery started in Egypt, but first outstanding surgery for hernia was done by Bassini in 1888 , followed by a century later by Lichtenstein introducing mesh repair in 1984.,2,3 Laparoscopic inguinal hernia repair introduced by Raft Ger in $1982 .{ }^{4}$ Then debate started for the choice of operation, laparoscopic or open hernia repair. Laparoscopic TAPP, TEP or open repair is going on debate for deciding superiority of laparoscopic procedure over open one. ${ }^{5}$ Those who favour laparoscopic surgery say that it is without scar, less painful, less time off work, ideal for bilateral hernia, recurrent hernia, with fewer complications. Those who are in favour of open surgery claim that hernia can be performed under local anaesthesia as day care surgery without reaching the abdomen and is cost effective. Comparing laparoscopic with open surgery it is said that primary goal should be to prevent recurrence, provide comfort to patient, reducing risks and increasing spectrum of benefits so the debate is going on for superiority. ${ }^{6}$

\section{OBJECTIVE}

To compare Laparoscopic transabdominal preperitoneal (TAPP) to open Lichtenstein inguinal hernia repair for operation time, acute postoperative pain, complications, hospital stay, time to return to work to find out which has better outcome. 


\section{MATERIAL AND METHOD}

It was a prospective randomized control trial study conducted at surgical department BVH /QAMC Bahawalpur from 1 July 2017 to 30 June 2018, on the patients above 18 years of age having unilateral inguinal hernia. The patients of recurrent hernia, previous abdominal surgery, obstructed hernia, co morbidities of cardiopulmonary disease were excluded from study. Patients entering the ward were divided into two groups randomly ending with 32 patients in Lichtenstein and 18 patients in transabdominal preperitoneal (TAPP) repair.

The patients were informed about the open and laparoscopic technique and written informed consent was taken. In Lichtenstein repair a suprainguinal incision was given and mesh was placed. In laparoscopic TAPP, three port technique was used. One $10 \mathrm{~mm}$ port in infra-umbilical region for camera, two $5 \mathrm{~mm}$ port at midclavicular line at umbilical level on both sides. $10 \times 15$ mesh was fixed with tracker. Same team operated all the patients and same set of instruments were used. Data collected on preformed Performa. Preoperative $1 \mathrm{gm}$ ceftriaxone was given to all patients. Numerical pain rating system (NPRS), 0 to 10 was used, 0 no pain, 1-3 mild,4-7 moderate,8-10 severe pain. Ketarolic injection $15 \mathrm{mg} / \mathrm{ml}$ was used for pain and repeated as required up to $90 \mathrm{mg} /$ day. Pain and use of analgesia was assessed in first 24 hours. The patients were followed after leaving the hospital on one week, one month, three month and six month for complications.

Data of patients were evaluated on set parameters of operation time, hospital stay, acute postoperative pain, time to return to work, immediate and delayed complications. Data analysed on SPSS 23. Student's t test, chie. Sq. test, Fischer test was used for statistics analysis at $P$ value of 0.05 at confidence interval of $95 \%$.

\section{RESULTS}

A total of 50 patients were part of study, of which 32 were of Lichtenstein repair and 18 laparoscopic transabdominal preperitoneal repairs. Age, gender and laterality shown in Table-I. Parameters regarding time consumption, operation time, hospital stay and return to work are evident in Table-II. Pain score, analgesia requirement, immediate and late complications are shown in Table-III.

\section{DISCUSSION}

A number of parameters are described to compare Lichtenstein mesh repair to transabdominal preperitoneal repair. In our study the operation time was significantly less in Lichtenstein group $37.96+13.66$ vs. laparoscopic group $48.77+9.92$. Other studies also has mentioned similar results. ${ }^{7,8}$ Scheuermann sorted out 557 studies and found out that only 8 having randomised controlled trial. In his meta-analysis Lichtenstein mesh repair time was 6.79 minutes less than laparoscopic group in 343 to 326 patients respectively. ${ }^{9}$ Ekulund et al found no difference in operation time. ${ }^{10}$

\begin{tabular}{|l|c|c|c|}
\hline \multicolumn{1}{|c|}{ Parameter } & Lichtenstein & TAAP & P-Value \\
\hline Age & $45.84+9.79$ & $44.94+9.82$ & 0.22 \\
\hline Gender & 30 & 18 & 0.21 \\
\hline Male & 2 & 0 & \\
Female & & & \\
\hline Laterality & 22 & 10 & 0.26 \\
Right & 10 & 8 & \\
Left & & & \\
\hline
\end{tabular}

Table-I. Age, gender and side involvement

\begin{tabular}{|l|c|c|c|}
\hline \multicolumn{1}{|c|}{ Parameter } & $\begin{array}{c}\text { Lichtenstein } \\
\mathbf{n = 3 2}\end{array}$ & $\begin{array}{c}\text { TAPP } \\
\mathbf{n = 1 8}\end{array}$ & P-Value (t test) \\
\hline Operation Time (min) & $37.96+13.66$ & $48.77+9.92$ & $<0.001$ \\
\hline Hospital stay (Days) & $2.28+0.79$ & $1.55+0.63$ & $<0.001$ \\
\hline Return to Work (Days) & $13.20+4.75$ & $10.47+3.59$ & $<0.001$ \\
\hline
\end{tabular}




\begin{tabular}{|l|c|c|c|}
\hline Immediate Complication & $\begin{array}{c}\text { Lichtenstein } \\
\mathbf{n = 3 2}\end{array}$ & $\begin{array}{c}\text { TAAP } \\
\mathbf{n = 1 8}\end{array}$ & $\begin{array}{c}\text { P-Value (Chie sq /Fischer } \\
\text { test) }\end{array}$ \\
\hline Pain score & $6.1+1.9$ & $5.27+0.94$ & $<0.001$ \\
\hline Analgesia & $4.25+0.84$ & $2+0.68$ & $<0.001$ \\
\hline Haematoma & $2(6.25 \%)$ & $0(0 \%)$ & 0.40 \\
\hline Seroma & $1(3.12 \%)$ & $2(11.11 \%)$ & 0.59 \\
\hline Wound infection & $3(9.37 \%)$ & $1(5.55 \%)$ & 0.54 \\
\hline Visceral/vascular injury & $0(0 \%)$ & $1(5.55 \%)$ & 0.36 \\
\hline Long-term Complications & $13(40.62 \%)$ & $3(16.66 \%)$ & - \\
\hline Chronic pain & $9(28.12 \%)$ & $2(11.11 \%)$ & 0.15 \\
\hline Recurrence & $1(3.12 \%)$ & $0(0 \%)$ & 0.64 \\
\hline Port site Hernia & $0(0 \%)$ & $1(5.55 \%)$ & 0.36 \\
\hline Numbness & $3(9.37 \%)$ & $0(0 \%)$ & 0.25 \\
\hline
\end{tabular}

Acute postoperative pain was assessed on numeric scoring system. The patients of TAPP suffered fewer episodes of acute postoperative pain in first 24 hours as compared to Lichtenstein group. The pain score was $5.2+0.94$ in TAPP vs. $6.1+1.9$ in laparoscopic group. In a study visual analog score (VAS) was $4.43+1.59$ in laparoscopic vs. $6.23+1.87$ in Lichtenstein group in first 12 hours postoperatively with $P$ value $0.05 .^{9}$ Most studies favour TAPP regarding pain. ${ }^{11,12}$ As a consequence requiring less analgesia $4.25+0.84$ in laparoscopic group than $2 \pm 0.68$ in Lichtenstein group in our study.

Postoperative Complications are infrequent in both groups. The usual complications in immediate postoperative period are haematoma (6.25\% vs. $0 \%$ ), seroma (3.125 vs $11.11 \%)$, wound infection $(9.37 \%$ vs. $5.55 \%)$, visceral/vascular $(0 \%$ vs. 5.55\%) in Lichtenstein and laparoscopic group respectively in our study. A meta-analysis showed haematoma in $24 / 388(6.18 \%)$ vs. $25 / 372(6.72 \%)$ seroma in21/338 (6.21\%) vs. $17 / 322$ (5.27\%), wound infection $3 / 316$, (0.94\%) vs. $7 / 300$ (2.33\%) TAPP and Lichtenstein group respectively but major haemorrhage in $8 / 395(2.02 \%)$ vs. $1 / 381$ $(0.26 \%)$ in laparoscopic vs. Lichtenstein was mentioned. Four out of 8 required conversions in the study. ${ }^{9}$ In our study no conversion was needed. Schmedt found haematoma and wound infection was frequent in Lichtenstein and seroma in laparoscopic group. He narrated that haematoma might remained unnoticed in laparoscopic group. ${ }^{7}$

The patients were discharged on settling the pain and immediate postoperative worries. Length of stay in hospital was found $2.28 \pm 0.79$ in Lichtenstein and 1.55 \pm 0.63 in laparoscopic group in our study. In a study hospital stay mentioned is 3.5 to 5 days but different hospitals have different strategy regarding discharge of patients. Mehmood has mentioned hospital stay $1.70 \pm 0.64$ vs. $2 \pm 0.77$ in Lichtenstein vs. laparoscopic group respectively narrating less time in open group but statistically insignificant. ${ }^{13}$

Lichtenstein group took more time to return to work (13.20 \pm 0.79$)$ as compared to laparoscopic group $(10.47 \pm 3.59)$; significantly less in endoscopic group. Scheuermann found 14-45 days vs. 1552 days in laparoscopic and Lichtenstein group with an average of 3.46 days less in endoscopic group. $^{9}$

Long term complications in hernia repair are chronic pain, recurrence of hernia, port site hernia and numbness. In our study $9 / 32$ (28.12\%) vs. $2 / 18(11.11 \%)$ suffered chronic pain in open and laparoscopic group respectively. Scheuermann described chronic pain in 19/299 (6.35\%) in TAPP vs. 37/284 (13.02\%) in laparoscopic group respectively. It was attributed to direct handling the nerves in inguinal canal. ${ }^{9}$ In our study 1 (3.12\%) patient had recurrence in open group and no recurrence in laparoscopic group. Recurrence rate of 1 to 5 percent has been mentioned in literature. A meta-analysis has mentioned recurrence of $9 / 337$ (2.67\%) and 6/322 (1.86\%) in laparoscopic and Lichtenstein group respectively but statistically insignificant. ${ }^{9}$ The recurrence rate especially in laparoscopic group depends upon 
experience of surgeon. ${ }^{14,15,16}$ Port site hernia happened in $1(5.55 \%)$ of patient of laparoscopic group in our study. Tamme in a study of 5203 patients had not found even single case of port site hernia but Fitzgibbons found $0.7 \%$ port site hernia in a series of 686 patients. ${ }^{17}$ Numbness was found in $3 / 32$ (9.37\%) in Lichtenstein and nil in laparoscopic group in our study. A study has shown $3 / 238$ (1.26\%) and 19/214 (8.87\%) in TAPP and open group respectively but found statistically insignificant. ${ }^{10}$ An explanation for genital and scrotal numbness in Lichtenstein group is that ilioinguinal and genitofemoral nerve injury are relatively more in open group. ${ }^{18,19}$

Lichtenstein is a cheap procedure and can be performed under local anaesthesia as day care without going inside abdomen; whereas laparoscopic repair although needing costly setup, experience and general anaesthesia is a scar less surgery with less postoperative discomfort and early return to work. ${ }^{20}$

\section{CONCLUSION}

we conclude that although there is insignificant difference in complication rate, Laparoscopic hernia repair, is better than Lichtenstein repair in terms of less postoperative pain, less hospital stay and early return to work.

Copyright@ 28 Dec, 2018.

\section{REFERENCES}

1. Jenkins J, O'Dwyer P. Inguinal hernias. Br Med J. 2008; 336:269-72.

2. Thorwald J, Bassini. The Triuph of surgery. $1^{\text {st }}$ ed. Great Britain: Jarold\&Sons; 1960:274-99.

3. Kingsnorth AN, Britton BJ, Morris PJ. Recurrent inguinal hernia after local anaesthetic repair. $\mathrm{Br} \mathrm{J}$ Surg. 1981; 68(4):273-5.

4. Ger R. The management of certain abdominal hernia by intra-abdominal closure of the neck of the sac. Preliminary communication. Ann R Coll Surg Engl. 1982; 64(5):342-4.

5. Eklund A, Rudberg C, Leijonmarck CE, Rasmussen I, Spangen L, Wickbom G, et al. Recurrent inguinal hernia: randomized multicenter trial comparing laproscopic and Lichtenstein repair. Surg Endosc. $2007 ; 21: 161-6$.
6. McCormack K, Scott NW, Go PM, Ross S, Grant AM; EU Hernia Trialists Collaboration. Laproscopic techniques versus open techniques for inguinal hernia repair. Cochrane Database Syst Rev. 2003; (1):1785.

7. Schmedt CG, Sauerland S, Bittner R. Comparison of endoscopic procedures vs Lichtenstein and other open mesh techniques for inguinal hernia repair: A meta-analysis of randomized controlled trials. Surg Endosc. 2005; 19(2):188-99.

8. Dedemadi G, Sgourakis G, Kraliotas C, Christofides T, Kouraklis G, Karaliotas C. Comparison of laproscopic and open tension-free repair of recurrent inguinal hernias: A prospective randomized study. Surg Endosc. 2006; 20(7):1099-104.

9. Scheuermann $U$, Niebisch $S$, Lyror $O$, Jansenwinkeln $B, G o c k e l$ I. Transabdominal preperitonial verus Lichtenstein operation for primary inguinal hernia-A systematic review and meta-analysis of randomized controlled trials. BMC Surgery. 2017; 17:2-10.

10. Eklund A, Rudberg C, Leijonmarck CE, Rasmussen I, Spangen L, Wickbom G, Wingren U, Montgomery A. recurrent inguinal hernia randomized multicenter trial comparing laproscopic and Lichtenstein repair. Surg Endosc. 2007; 21(4):634-40.

11. Anadol ZA, Erosy E, Taneri F, Tekin E. Outcome and cost comparison of laparoscopic transabdominal preperitoneal hernia repair versus open Lichtestein technique. J Laparoendosc Adv Surg Tech A. 2004; 14(3):159-63.

12. Salma U, Ahmed I, Ishtiaq S. A comparison of post-operative pain and hospital stay between Lichtenstein's repair and Laparoscopic Transabdominal Preperitoneal (TAPP) repair of inguinal hernia: A randomized controlled trial. Pak J Med Sci. 2015; 31(5):1062-6.

13. Mehmood Z, Islam Z, Shah SS. Open Lichtenstein repair versus laparoscopic transabdominal preperitoneal repair for inguinal hernia. JSP Pak. 2014; 19:54-56.

14. Grant Am. EU Hernia Trialists collaborationLaparoscopic versus open groin hernia repair: Metaanalysis of randomised trials based on individual patient data. Hernia. 2002; 6(1):2-10.

15. Bittner R, Schmedt CG, Schwarz J, Kraft K, Leibl BJ. Laparoscopic transperitoneal procedure for routine repair of groin hernia. Br J Surg. 2002; 89(8):1062-6. 
16. Tamme C, Scheidbach $H$, Hampe C, Schneider C, Kockerling F. Totally extraperitoneal endoscopic inguinal hernia repair (TEP). Surg Endosc. 2003; $17(2): 190-5$.

17. Fitzgibbons RJ , Cramps J, Cornet DA, Nguyen NX, Litke BS, Annibali R, Salerno GM. Laproscopic inguinal herniorrhaphy. Results of multicenter trial. ANN Surg. 1995; 221(1):3-13.

18. Wellwood J, Sculpher MJ, Stroker D, Nicholls GJ, Geddes C, Whitehead A, Singh R, Spiegelhalter D. Randomised controlled trial of laparascopic versus open inguinal hernia mesh repair: Outcome and cost. BMJ. 1998; 317:103-10.
19. Loos MJ, Roumen RM, Scheltinga MR. Classifying post-herniorrhaphy pain syndromes following elective inguinal hernia repair. World J Surg. 2007; $31(9): 1760-5$.

20. Fitzgibbons RJ, Filipi CJ, Quinn TH. Inguinal Hernias. In: Brunicardi FC, Anderson DK, Billiar TR, Dunn DL, Hunter JG, Pollock RE, editors. Scwartz's Principles of Surgery. $8^{\text {th }}$ ed. USA: The McGraw-Hill Companies, Inc; 2005: 1354.

\section{AUTHORSHIP AND CONTRIBUTION DECLARATION}

\begin{tabular}{|c|c|c|c|}
\hline Sr. \# & Author-s Full Name & Contribution to the paper & Author $=\mathbf{s}$ Signature \\
\hline 2 & $\begin{array}{l}\text { Khurram Niaz } \\
\text { Fatima Tahir }\end{array}$ & $\begin{array}{l}\text { Conception and design, Collection } \\
\text { and assembly of data, analysis } \\
\text { and interpretation, drafting, critical } \\
\text { revision, statistical analysis. } \\
\text { Collection and assembly of data, } \\
\text { drafting. } \\
\text { Data collection, statistical analysis. }\end{array}$ & $v$ \\
\hline & Humaira Sobia & Interpretation and critical revision. & \\
\hline
\end{tabular}

